\title{
The Application of Eco-translatology Theory to College Translation Courses
}

\author{
Man Zhai \\ School of Foreign Languages \\ Jilin Business and Technology College \\ Changchun, China
}

\begin{abstract}
Eco-translatology here is not an independent subject category, but can be understood as the translation research through an ecological approach or an ecological perspective to translation study. By focusing on the integrity of the translation ecosystem, from the perspective of ecotranslatology, taking the narrative way of eco-translatology, the Eco-translatology makes new descriptions and explanations of the nature, process, standards, principles, methods and phenomena of translation. It is pointed out in this paper that the Students play a dominant and central role in translation teaching and follow the translation methods of three-dimensional transformation, making an adaptive selection for the translation. This paper aims to explore the feasibility of college English translation teaching from the perspective of eco-translatology. Based on the analysis of the current situation of college English translation teaching, this paper attempts to explore the nonEnglish professional translation teaching mode under the guidance of ecological translation theory, so that translation teaching can be carried out anytime and anywhere.
\end{abstract}

Keywords-eco-translatology theory; college English translation course; learning strategy

\section{INTRODUCTION}

Eco-translatology can be understood as an ecological approach to translation studies or translation studies from an ecological perspective. Since "Eco-translatology" involves at least "Ecology" and "Translatology", it is also an interdisciplinary cross-disciplinary study. "Ecology" is defined as "the science of biology that studies the relationship between organisms and the environment as well as the relationship between organisms”. Eco-translatology is an interdisciplinary and multidisciplinary product that is consistent with the trend of the times, society and academic development. At the same time, it is also an extension of contemporary translation studies from a new perspective, and reflects the development trend of translation theory research from a single subject to interdisciplinary integration. The eco-translatology emphasizes the integrity of translation eco-environment, translator-centered and translation as adaptation and selection. As the deepening of human understanding to the logical relationship between organisms and environment, the modern ecology has expanded to study the logical relationship between humans and nature. The popular environmental protecting movement that emerged in the 1960s and 1970s further moved the Ecology away from the biological field, and it has risen to study the essential relationship between humans and nature. In recent years, in the research field of humanity and social science, the term "Ecology" has been transferred into a collection of natural health, balance and "harmonious coexistence". Ecology is based on holistic science, and its research methods emphasize the integrality of interconnectedness and interaction.

"Translatology" is a discipline that studies the rules and art of translation. As a part of translatology, translation theory is a rational understanding and highly abstraction of a series of translation knowledge such as translation essence, principle, process, method and standards. The translation as adaptation and selection produced in recent years is based on the basic principles of "natural selection" and "survival of the fittest" in the theory of biological evolution, and follow the classic wisdom of the "harmony between man and nature" and "moderate harmony" in ancient Chinese philosophy, and then proposed the translation theory of translation as adaptation and selection.

\section{THE DEVELOPING AND INTERPRETATION OF ECO-} TRANSLATOLOGY

\section{A. The Concept of Eco-translatology}

On the basis of ecology and translatology studies, especially the translation theories, from the perspective of translation ecology, taking the essence of ecology and the overall of the translation, based on the reality of translation, it comes into being a series of terms and concepts in related researches, including "translational eco-environment" "translation ecosystem" "translator adaptation", "translator selection”, "surviving and Prioritizing “, "symbiosis interaction” and so on. The sustained theory researches, application researches and results accumulation make "eco-translatology" stand out.

From a comprehensive perspective, the eco-translatology is not only a "metaphor" but also a "reality". The so-called "metaphor" refers to the holistic studies based on the principle that make a metaphorical analogy translational ecology and natural ecology. The so-called "reality" refers to the study of the relationship between the translator and the translational eco-environment, especially the research of the living circumstances and capability development of translators in the translation ecology. In other words, by focusing on the integrity of the translation ecosystem, from the perspective of ecotranslatology, taking the narrative way of eco-translatology, the eco-translatology makes new descriptions and explanations of

This is the research findings of Program the application and research of Eco- translatology over college translation courses supported by high educational institute of Jilin province, program number is JGJX2018D120. 
the nature, process, standards, principles, methods and phenomena of translation.

\section{$B$. The generating background of eco-translatology}

1) Global ecological tide for intercross subjects: The presentation of every idea has its own profound background and social thoughts. The emergence of the eco-translatology is consistent with the development direction of social and academic in this era. It is a reflection of economic society transformation in translatology researches. As we all know, since the 1960s, human society has gradually begun to transform from industrial civilization to ecological civilization.

2) The cultural dimension: Chinese translation scholars advocate the concept of eco-translatology, which also because of the rich ancient ecological wisdom that Chinese can learn from. This is an ecological wisdom characterized by "the combination of human and nature", "learn from nature", "Moderation is blameless" and "people-oriented". Confucius praised the teachings of" Sincerely adhere to the right and impartial way "; Mencius clearly stated that " The principle of the universe exists in human nature"; Han Fei believes: "Things change when the condition changes", "Changes come when things are different"; Liu Yuxi advocates the idea that "Nature and human society have their own laws and functions, and sometimes human win the nature, sometimes nature wins"; Dai Zhen said: " Human beings are the highest creatures in nature "; Wang Yangming stated that "everything in the heavens and the earth is one" ; In modern times, Yan Fu stated outright that "The contenders, fight for things standing for themselves; Natural selection, choose the ones who can adapt to nature best " "As with the plants and animals, so with human beings", etc. All of these include the classical forms of "nature", "life", "survival", "moderate", "human", "harmony" and other ecological ideas. It has become a valuable intellectual resource for gestating and forming the eco-translatology. These original books that are highly valued by many international philosophers and ideologists, is undoubtedly an important fulcrum for Chinese translation scholars to put forward the concept of the eco-translatology.

3) The communicational dimension: The global trend of "returning to the basics" and "returning to nature" has led more and more people to advocate ecological food, ecological furnishing, ecological tourism and healthy and balanced ecological environment. In the academic world, "environmentalism has transcended the boundaries of science, geography, and social sciences and entered the 'humanities". People are "working hard to shift their focus on culture to a broader living environment”. Under such development trends, researches on various disciplines with ecological properties have sprung up. In addition to many disciplines such as ecocriticism, ecological aesthetics, ecological literature, ecological politics, ecological theology, ecological philosophy, ecological library science, ecological Marxism, ecopolis theory, ecological social economics, etc. The linguistic disciplines that are closely related to translation studies include environmental linguistics, green grammar, linguistic environment and environmental linguistics, ecological lexicology, language and ecology research, language acquisition ecology, language evolution ecology, linguistic diversity and biodiversity research, etc.
In the research and description of the above-mentioned translation scholars, most of them use the "metaphor" or " reality" approach, using the terminology and concepts in typical ecological sense, including "ecology", "environment", "survival", "adaptation" and even "ecology of translation". It can be seen that these studies not only provide a perspective for studying eco-translatology, but also paved the way for further research.

\section{ThE FEASIBILITY ANALYSIS OF APPLYING ECO- TRANSLATOLOGY TO COLLEGE ENGLISH TRANSLATION TEACHING}

\section{A. The Eco-translatology Provides Theoretical Basis for Translation Teaching}

The three principles of ecological translation theory can provide theoretical supports for college English translation teaching, namely the holistic theory of ecological translation environment, the translator-centered theory and the adaptation theory.

1) The ecological translation environment holism emphasizes the importance of extracurricular learning: Ecotranslatology believes that the eco-environment of translation means: "In translation, the world represented by the original text, the source language and the translated language, that is, the whole of the interconnected interaction of the language, communication, culture, society, and the authors, readers, and mandators". Emphasizing the ecological holism means that different elements within the system are related to each other, and the interaction constitutes an organic whole. The whole function is greater than the sum of the functions of the various parts, rather than the simple sum of the functions of the various components, it will produce the effect of "affecting the whole with one influence", that is, the holistic effects.

At present, the current situation of college English translation teaching is not optimistic: "very few teaching hours, and the "Comprehensive Translation" only has 2 class hours per week, the number of teaching weeks is only 17 weeks, and a total of 34 hours in a semester". It can be seen that translation teaching is marginalized in non-English major. Fortunately, the eco-translatology provides a new perspective and theoretical supports for this situation. The overall ecological environment of translation teaching includes not only in-class teaching, but also the extracurricular teaching. The translation holistic theory organically links the in-class teaching with the extracurricular teaching. The in-class teaching highlights the teachers' "teaching", the extracurricular teaching highlights the students' "learning", the overall development of in-class teaching and extracurricular teaching, achieving the overall development of translation teaching, would improve the level of students' translation. Only by paying attention to the interaction between the various elements within the system can we promote the dynamic balance of the whole system and the steady development.

2) Translator-centeredness emphasizes translators' subjectivity:

In the process of translation operation, all adaptation and selection behaviors are decided and implemented by the translators. The translators, leading the translation process, is 
the sum of all the "contradictions" in the translation process. The idea of eco-translatology places translators in the selection activities of the Chinese translation eco-environment of the entire translational eco-environment. In the process of translation, translators should follow the translation method of three-dimensional transformation, that is, multi-dimensional adaptation and adaptive selection are made in the language dimension, cultural dimension and communication dimension. The higher the integration adaptive selectivity is, the higher the quality of translation is.

As a translator, students should actively adapt to the translational eco-environment of the translated texts before translation, such as the original text, the original author and the ideology of the original text, as well as the readers of target language, sponsors and the ideology of the target texts. During the process of the translation, students should constantly make selections in three dimensions: language dimension at the level of vocabulary, sentence, rhetoric and stylistic, cultural dimension of politics, history, religion, etc., and the communicative dimension aiming to realize the communicative intention of the original texts. In the process of translation, different versions of the translation may appear, and this requires students to actively communicate with their classmates, ask the teacher for advice, and get the translation with the highest Adaptive selectivity based on the principle of "survival of the fittest”.

\section{B. Concrete Implementation of Translation Teaching Mode From the Perspective of Eco-translatology}

The specific operations of eco-translatology for translation teaching mainly involve the following three processes: teachers layout assignments, students daily attendance, and students translation communication. Teachers can use the Internet platform such as QQ, WeChat to establish three translation groups with different roles for specific operations. The Core Concerns About Selection and Adaptation

1) The assignments should highlight the integrity: In the teaching mode of eco-translatology, teachers assign the assignments to students not only to send the translated texts, but also to supplement the background knowledge of translated texts, so as to establish an translational eco-environment combining the texts and the culture for translation. Teachers should make adequate preparation for the supplementary background knowledge and select texts of various types that are of high interest to students. Moreover, within the group, the background of the translation text should be introduced by voice, text, picture or PPT. Here is a famous translation of the famous American writer Hemingway, which is taking as an example to demonstrate how to pave the way for translation practice from the cultural background level: Life always makes us black and blue, but later, those places become stronger injured. Teachers can briefly introduce Hemingway's rich life experiences firstly: Hemingwei was a soldier, a war correspondent, and later became a writer. During the World War, he underwent two crashes, three car accidents, and 237 pieces of shrapnel were removed in the hospital. By giving specific examples, students will have a better understanding of Hemingway's "tough guy image" and be touched by his spirit of "can't be destroyed", thus, it is not so difficult to translate black and blue into "a mass of bruises". A complete ecological translation environment includes not only the original author, but also the social, cultural, and communicative introduction behind the original author. Therefore, any translation must be combined with the background, lack of macro background and experience of the beauty of culture, and only pay too much attention to the translation of words, which is not conducive to the presentation of the overall effects. Therefore, translation should be proceed from the whole, taking all factors into consideration, paying attention to the combination of various elements within this system, and transition from cultural background to translation practice.

\section{2) Daily attendance mobilizes the subjective initiative:}

Translation is an alternate cycle process in which translators make adaptation and selection. Therefore, translators need to sum up the translation eco-environment of various types of texts through a lot of translation exercises, repeatedly consider the translation and make adaptive choices. Due to the limited time in class and the low enthusiasm of students for translation after class, it is difficult for students to translate under the higher subjective initiative. In this case, teachers can set up a daily translation attendance group. The specific mode of operation is as follows: every Sunday, three translated texts in the form of Word are published in the group, which can be a poem, a famous quote, a short story, a short essay with unlimited content and subject matter, and teachers will adjust according to the actual situation. Students translate the text into the exercise book on Monday, Wednesday and Friday and take photos, and then send the photos to the group for attendance. Each time, the number of students was counted by a classmate. This not only urges each student to complete their own translation, but also allows them to see the translation of other students and make comparison to learn from each other. The author finds that there are some problems such as delay time, low efficiency and no comparison when students do translation alone. However, after using translation attendance in group, the enthusiasm of students is significantly improved. Usually, only a few students fail to complete the punching in the prescribed time due to special circumstances. In terms of the formation of students' translation habits and the improvement of translation speed, this intra-group translation attendance mode produces an effect of $1+1>2$. As the main body of the translation process and the cornerstone of the translation, students give full play to the translator's subjective initiative from passive acceptance to active exploration, and the translation level is also strengthened.

\section{CONCLUSION}

This study demonstrates the feasibility of College English translation teaching from the perspective of eco-translatology. After three months of teaching experiments, the results show that the application of eco-translatology in College English translation teaching is effective. The new teaching model breaks the space and time and enables students to carry out translation practice anytime and anywhere. Teaching becomes more flexible and students give full play to the subjective initiative of translators, from passive acceptance to active adaptation and selection. Under the supervision of teachers, students have improved their translation ability and developed creative thinking, self-confidence and social communication 
skills in the process of interaction with teachers and learning resources. The new model is conducive to cultivating compound practical talents for the society. In a word, ecotranslatology plays a promotive role in College English translation teaching, making the "solo" of teacher in traditional translation teaching become the "symphony" played by teachers and students. However, this study also has some limitations. Because of the relatively limited number of samples and experimental time, this study only confirmed that the new model can promote the teaching of English translation in universities, but the extent to which students' translation ability can be improved remains to be further studied. References

\section{REFERENCES}

[1] Anderson, J.R. Cognitive Psychology and Its Implication [M]. New York: W.H. Freeman, 1985.

[2] Barkaoui K. Think-aloud protocols in research on essay rating: An empirical study of their veridicality and reactivity [J]. Language Testing, 2011(1):51-75.

[3] Bowles M.A. The Think-Aloud Controversy in Second Language Research [M]. New York: Routledge, 2010.

[4] Leow R.P. \& Morgan-Short K. To think aloud or not to think aloud: The issue of reactivity in SLA research methodology [J]. Studies in Second Language Acquisition, 2004(1):35-57.

[5] Monacelli, C. Self-preservation in Simultaneous Interpreting [M]. Amsterdam: John Benjamins,2009.

[6] Nida, E.A. Language, Culture and Translation [M]. Shanghai: Shanghai Foreign Language Education Press, 1993: 109-110.

[7] Sanz C, Lin H.J., Lado B, Bowden H.W. \& Stafford C.A. Concurrent verbalizations, pedagogical conditions, and reactivity: Two CALL studies [J]. Language Learning, 2009(1):33-71. 